\title{
FoxO transcription factors are required for hepatic HDL cholesterol clearance
}

\author{
Samuel X. Lee, ${ }^{1}$ Markus Heine, ${ }^{2}$ Christian Schlein, ${ }^{2}$ Rajasekhar Ramakrishnan, ${ }^{3}$ Jing Liu, ${ }^{3}$ Gabriella Belnavis, ${ }^{1}$ Ido Haimi, ${ }^{1}$ \\ Alexander W. Fischer, ${ }^{2}$ Henry N. Ginsberg, ${ }^{3}$ Joerg Heeren, ${ }^{2}$ Franz Rinninger, ${ }^{2,4}$ and Rebecca A. Haeusler ${ }^{1,5}$ \\ 'Naomi Berrie Diabetes Center, Columbia University College of Physicians and Surgeons, New York, New York, USA. ²Department of Biochemistry and Molecular Cell Biology, University Medical Center \\ Hamburg Eppendorf, Hamburg, Germany. ${ }^{3}$ Department of Medicine, Columbia University College of Physicians and Surgeons, New York, New York, USA. ${ }^{4}$ Department of Internal Medicine III, University \\ Medical Center Hamburg Eppendorf, Hamburg, Germany. ${ }^{5}$ Department of Pathology and Cell Biology, Columbia University College of Physicians and Surgeons, New York, New York, USA.
}

Insulin resistance and type 2 diabetes are associated with low levels of high-density lipoprotein cholesterol (HDL-C). The insulin-repressible FoxO transcription factors are potential mediators of the effect of insulin on HDL-C. FoxOs mediate a substantial portion of insulin-regulated transcription, and poor FoxO repression is thought to contribute to the excessive glucose production in diabetes. In this work, we show that mice with liver-specific triple FoxO knockout (L-Fox01,3,4), which are known to have reduced hepatic glucose production, also have increased HDL-C. This was associated with decreased expression of the HDL-C clearance factors scavenger receptor class B type I (SR-BI) and hepatic lipase and defective selective uptake of HDL cholesteryl ester by the liver. The phenotype could be rescued by re-expression of SR-BI. These findings demonstrate that hepatic FoxOs are required for cholesterol homeostasis and HDL-mediated reverse cholesterol transport to the liver.

\section{Introduction}

The liver is a critical site for maintaining metabolic homeostasis. In hepatocytes, the forkhead transcription factors of the FoxO subfamily FoxO1, FoxO3, and FoxO4 (FoxOs) mediate a substantial portion of insulin-regulated gene transcription (1-5). During fasting, FoxOs are active, whereas insulin signaling suppresses FoxO activity via Akt-mediated phosphorylation and nuclear exclusion $(6,7)$. The 3 FoxOs work in concert to promote expression of their target genes (8). Previously, we have demonstrated that liver-specific ablation of these 3 hepatic FoxOs in mice prevents the induction of glucose-6-phosphatase and the repression of glucokinase during fasting, thereby increasing lipogenesis at the expense of glucose production (9). FoxOs are also required for the expression of multiple other genes involved in liver metabolic pathways (10-12). These findings demonstrate that hepatic FoxOs play a vital role in maintaining proper glucose and lipid homeostasis.

The liver also plays an essential role in cholesterol metabolism. One important role is that of facilitating the clearance of cholesterol from circulating high-density lipoprotein (HDL) particles into the liver, where it can be converted to bile acids or transported directly into the bile to be excreted in the feces (13, 14). HDL cholesterol (HDL-C) is primarily cleared by scavenger receptor class B type I (SR-BI), a liver membrane receptor that mediates selective HDL cholesteryl ester (CE) uptake, defined as lipid internalization independent of holoparticle uptake $(15,16)$.

Authorship note: SXL and MH contributed equally to this work. Conflict of interest: The authors have declared that no conflict of interest exists. Submitted: April 4, 2017; Accepted: February 1, 2018.

Reference information: J Clin Invest. 2018;128(4):1615-1626. https://doi.org/10.1172/JCI94230.
Acting alongside SR-BI is the enzyme hepatic lipase (HL) (17). Studies show that (a) HL is a liver-secreted enzyme that hydrolyzes triglycerides and phospholipids and is involved in processing large lipid-rich HDL into smaller HDL particles (18), and (b) the ligand-binding activity of HL may mediate interactions of lipoproteins with SR-BI or the plasma membrane, thus facilitating selective HDL-CE uptake (19-24). As such, mice lacking expression of either SR-BI or HL have elevated levels of HDL-C and impaired HDL-C clearance by hepatocytes (14, 25-28).

In the current study, we used mice with liver-specific ablation of 3 hepatic FoxOs (L-FoxO1,3,4) $(8,9)$ and littermate controls with the genotypes Foxo1 $1^{f / f l}$, Foxo $3^{f / f l}$, and Foxo $4^{f / Y}$ to explore the role of hepatic FoxOs in regulating HDL-C metabolism. We observed that L-FoxO1,3,4 mice had an increase in plasma HDL-C, especially when challenged with a Western-type diet (WTD). Moreover, we also found that hepatic FoxOs are required for the expression of the HDL-C clearance factors SR-BI and HL, suggesting that selective HDL-CE uptake by the liver may be diminished in L-FoxO1,3,4 mice. In order to directly measure selective HDL-CE clearance, metabolic studies were performed using HDL that was radiolabeled in both the protein $\left.{ }^{125} \mathrm{I}\right)$ and lipid $\left(\left[{ }^{3} \mathrm{H}\right]\right)$ moieties. We found that selective HDL-CE uptake by the liver was reduced in L-FoxO1,3,4 mice in vivo as well as in isolated L-FoxO1,3,4 primary murine hepatocytes in vitro. Moreover, the accumulation of HDL-C in L-FoxO1,3,4 mice was attenuated by the rescue of SR-BI expression. Thus, our data indicate that the increase in plasma HDL-C in L-FoxO1,3,4 mice was primarily a consequence of reduced HDL lipid uptake by the liver. These findings suggest that, in addition to the established effects on glucose and triglyceride metabolism, hepatic FoxOs are required for HDL-mediated reverse cholesterol transport, a key mechanism of lipid homeostasis in vivo. 

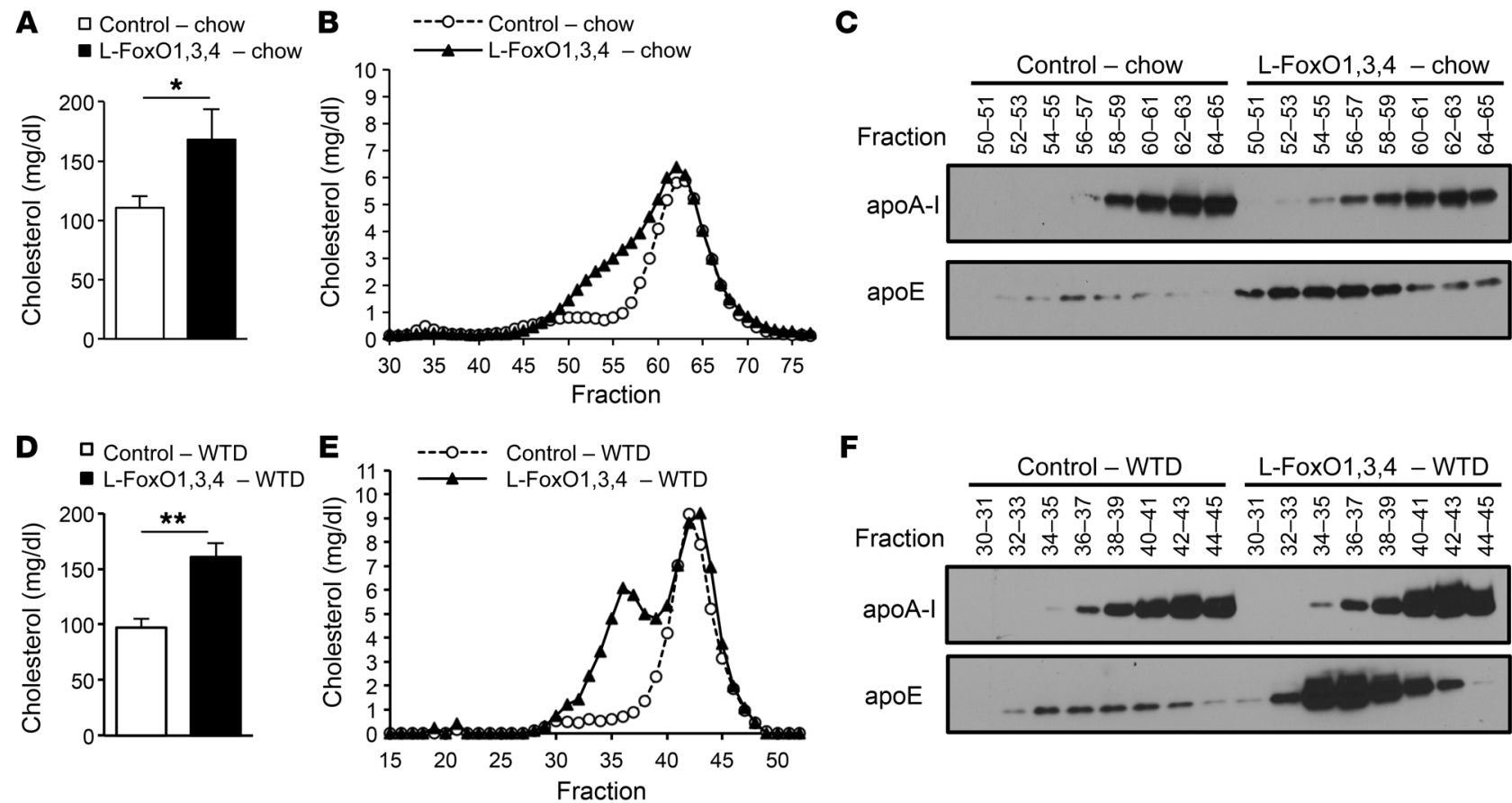

Figure 1. Plasma cholesterol profiles of chow-fed and WTD-fed L-Fox01,3,4 mice. (A) Total plasma cholesterol in chow-fed L-Fox01,3,4 mice and littermate controls after a 5-hour fast $(n=5)$. Data are presented as the mean \pm SEM. (B) Cholesterol levels in plasma fractionated by FPLC in the same mice as in $\mathbf{A}$. (C) Western blot of plasma apoA-I and apoE from pooled pairs of fractionated plasma obtained from FPLC in B. (D) Total plasma cholesterol levels in WTDfed L-Fox01,3,4 mice and littermate controls after a 5-hour fast $(n=5)$. (E) Cholesterol levels in plasma fractionated by FPLC in the same mice as in $\mathbf{D}$. (F) Western blot of plasma apoA-I and apoE from pooled pairs of fractionated plasma obtained from FPLC in E. Independent FPLC cholesterol profiles for both chow-fed and WTD-fed mice yielded qualitatively identical results. Data are presented as the mean \pm SEM. ${ }^{*} P<0.05$ and ${ }^{* *} P<0.01$, by Student's $t$ test.

\section{Results}

Deletion of hepatic FoxOs increases cholesterol accumulation in large HDL particles. We first measured plasma cholesterol in chow-fed mice and found 50\% higher plasma cholesterol levels in L-FoxO1,3,4 mice compared with levels in littermate controls (Figure 1A). In order to determine the distribution of cholesterol with respect to lipoprotein fractions, we separated the plasma by fast protein liquid chromatography (FPLC) and found that chowfed L-FoxO1,3,4 mice had increased HDL-C and accumulation of cholesterol in the fractions that eluted similarly to large HDL (Figure 1B). We performed Western blot analysis of these fractions and found that apoA-I, the major apolipoprotein of HDL, was shifted to the left, indicating larger HDL particles. We also found a leftward shift of apoE (Figure 1C), which is consistent with the well-established characteristics of large, spherical HDL particles $(29,30)$. In contrast, apoB-containing particles eluted much earlier, peaking at fractions 46-48 (data not shown) and disappearing by fraction 52 , indicating that there was little to no difference in LDL-C between genotypes. There were no differences in total plasma apoA-I levels (Supplemental Figure 1A; supplemental material available online with this article; https://oi.org/10.1172/ JCI94230DS1), suggesting that the leftward shift of apolipoprotein A-I (apoA-I), apolipoprotein E (apoE), and HDL-C indicates the presence of larger HDL particles in L-FoxO1,3,4 mice.

Next, we challenged the mice with a WTD consisting of $21 \%$ milkfat and $0.2 \%$ cholesterol. The WTD is known to increase plasma cholesterol levels and to induce atherogenesis in susceptible strains (31). After 3 weeks of WTD feeding, L-FoxO1,3,4 mice showed 65\% higher plasma cholesterol levels compared with levels in WTD-fed controls (Figure 1D). The cholesterol profile in the knockout mice was exacerbated on this diet, showing an accumulation of cholesterol in fractions that eluted similarly to large HDL (Figure 1E). Consistent with this, there was a leftward shift in apoA-I (Figure 1F). We also detected an abundant accumulation of apoE in these shifted fractions, similar to what is seen in other experimental mouse models with elevated HDL levels $(14,32)$. Mice on the WTD showed no differences in total plasma apoA-I levels (Supplemental Figure 1B). These data support the hypothesis that hepatic FoxOs play a role in HDL-C metabolism.

FoxOs are required for the expression of $S R-B I$ and hepatic lipase. To identify contributors to the accumulation of plasma HDL-C in L-FoxO1,3,4 mice, we queried microarrays from livers of L-FoxO1,3,4 mice (9) for genes involved in HDL synthesis and clearance (Supplemental Table 1). We found no differences in genes regulating HDL synthesis or biliary excretion, including Abca1, Apoa1, Apoa2, Lcat, Apoe, Abcg5, and Abcg8. We also found no significant differences in Apoc3, Srebp2, Hmgcr, or Pltp. However, L-FoxO1,3,4 mice showed reduced expression of 2 genes involved in HDL-C clearance: scavenger receptor class B member 1 (Scarb1),which encodes SR-BI, and lipase C, hepatic type (Lipc), which encodes HL. Using quantitative PCR (qPCR), we verified that $\mathrm{L}-\mathrm{FoxO} 1,3,4$ mice showed significant reductions in Scarb1 and Lipc during both chow and WTD feeding (Figure 2, A and B). We also verified that there were no differences in Abca1, Apoa1, Apoa2, Apoc3, Apoe, Lcat, Srebp2, Hmgcr, Abcg5, or Abcg8. qPCR showed an increase in Pltp expression, however increased 


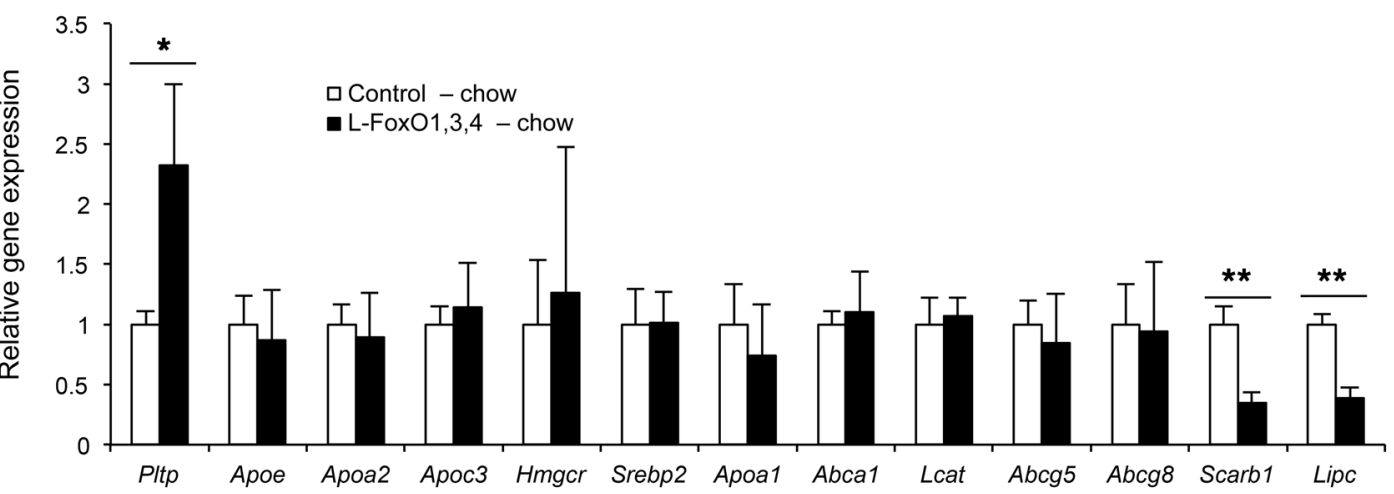

B

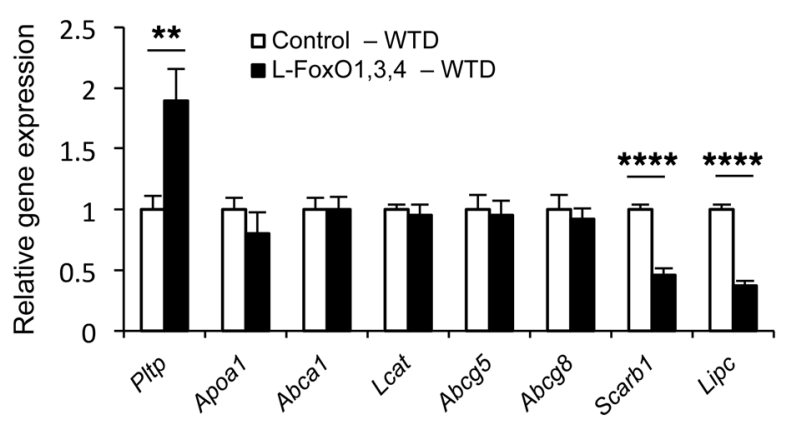

C

Diet $\frac{\text { Control }}{\text { Chow WTD }} \frac{\text { L-FoxO1,3,4 }}{\text { Chow WTD }}$

SR-Bl/actin $\overline{1.00 \pm 0.16} \overline{0.92 \pm 0.18} \overline{0.14 \pm 0.08 \S \S} \underline{0.09 \pm 0.03^{t \dagger}}$

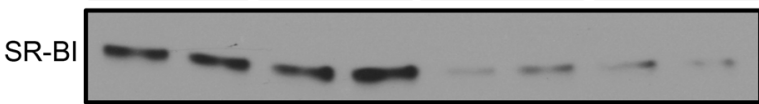

Actin
D

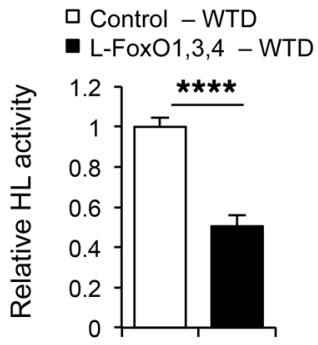

Figure 2. Defects in HDL metabolism genes due to ablation of hepatic FoxOs. (A and B) Relative hepatic gene expression by qPCR in (A) chow-fed L-Fox01,3,4 mice and littermate controls $(n=4-5)$ and (B) WTD-fed L-Fox01,3,4 mice and littermate controls $(n=6-7)$. (C) Representative Western blot of hepatic SR-BI expression in both chow-fed and WTD-fed L-Fox01,3,4 mice and littermate controls. SR-BI/actin denotes relative SR-BI expression levels by densitometric scanning ( $n=4$ /group total). (D) Relative plasma HL activity in WTD-fed L-Fox01,3,4 mice and littermate controls $(n=5-7)$. ${ }^{*} P<0.05,{ }^{* *} P<0.01$, and ${ }^{* * * *} P<0.0001$; $\$ \$ P<0.01$ between chow-fed L-Fox01,3,4 mice and littermate controls; ${ }^{\dagger+} P<0.01$ between WTD-fed L-Fox01,3,4 mice and littermate controls by Student's $t$ test. Data are presented as the mean \pm SEM.
Pltp alone is insufficient to increase HDL-C (33). These data suggest that the increase in plasma HDL-C in L-FoxO1,3,4 mice is due to defective clearance.

We next confirmed that these decreases in Scarb1 and Lipc mRNA resulted in decreases at the protein level. By Western blotting, we found that in both chow-fed and WTD-fed mice, SR-BI protein levels decreased significantly $(>85 \%)$ in liver lysates isolated from L-FoxO1,3,4 mice compared with levels in control mice
(Figure 2C). Consistent with what was observed from the gene expression data, we found no changes in liver ABCA1 protein levels between L-FoxO1,3,4 and control mice fed either chow or a WTD (Supplemental Figure 2). To investigate HL, we measured its activity in nonheparinized plasma $(34,35)$. Compared with controls, L-FoxO1,3,4 mice had a 50\% decrease in HL activity (Figure 2D). Taken together, these data demonstrate that hepatic FoxOs are required for normal expression of both SR-BI and HL.
Figure 3. Plasma decay kinetics of ${ }^{125}$ I-TC-/[ $\left.{ }^{3} \mathrm{H}\right] \mathrm{CEt}-W T-H D L$ in chow-fed L-Fox01,3,4 mice. (A and B) ${ }^{125}$ I-TC-/ $\left[{ }^{3} \mathrm{H}\right] \mathrm{CEt}-\mathrm{WT}-\mathrm{HDL}$ was injected i.v. into chow-fed L-Fox01,3,4 mice and littermate controls. Thereafter, over a 24 -hour period, blood samples were harvested periodically, and plasma was analyzed for ${ }^{25}$-TC (crosses) and $\left.{ }^{3} \mathrm{H}\right]$ CEt (circles). The $y$ axis represents the fraction of the tracer in plasma (percentage). Shown is a trace from a representative mouse from each genotype, with (A) control and (B) L-Fox01,3,4 mice. The experiment was performed in 7 control and $5 \mathrm{~L}-F o x 01,3,4$ mice.
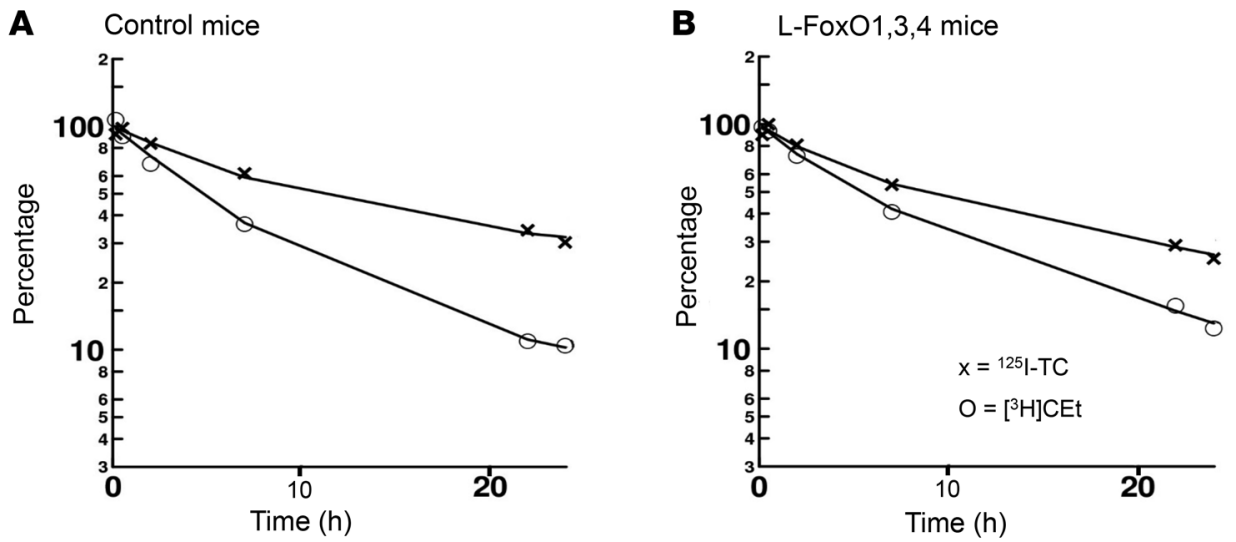
A
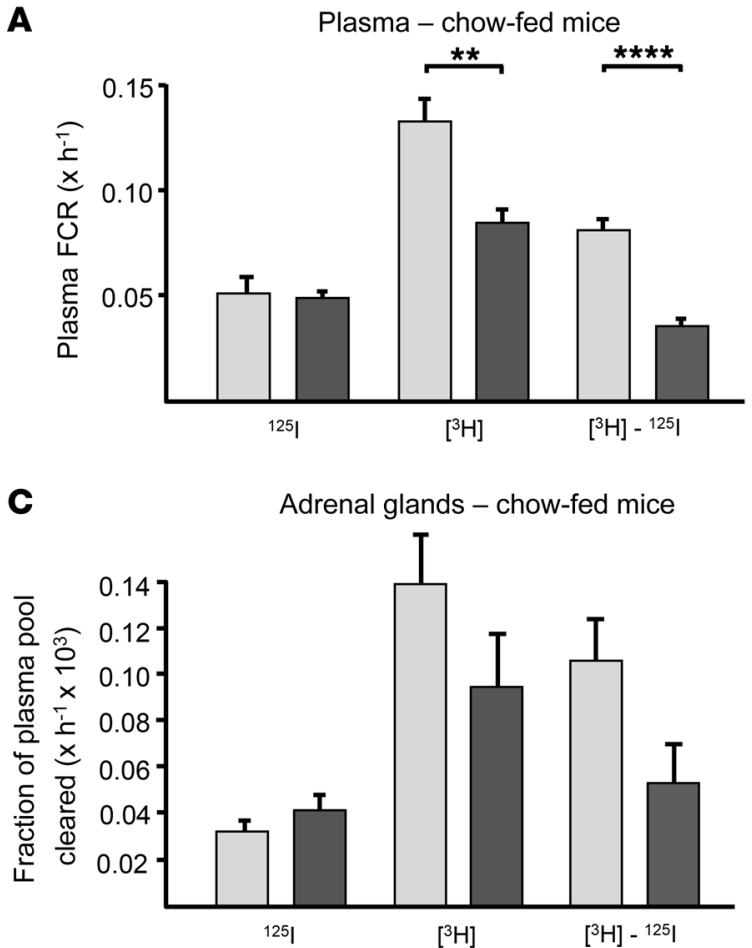

B

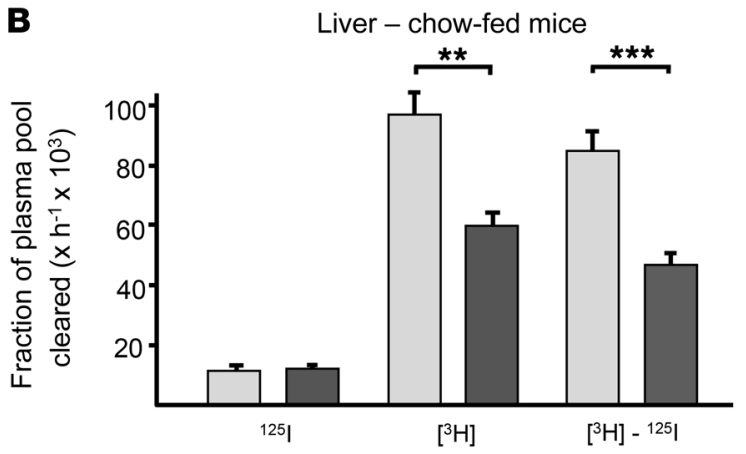

D

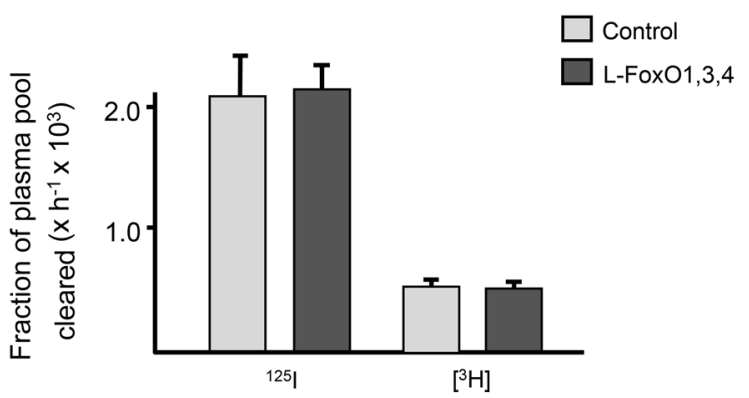

Figure 4. Plasma FCRs and tissue tracer uptake rates for ${ }^{125}$ I-TC- $/\left[{ }^{3} \mathrm{H}\right] \mathrm{CEt}-\mathrm{WT}-\mathrm{HDL}$ in chow-fed L-Fox01,3,4 mice. ${ }^{125} \mid \mathrm{TC}-/\left[{ }^{3} \mathrm{H}\right] \mathrm{CEt}-\mathrm{WT}-\mathrm{HDL}$ was injected i.v. into chow-fed L-Fox01,3,4 mice and littermate controls. (A) During the subsequent 24-hour period, blood was harvested periodically to determine the plasma decay of both tracers. ${ }^{125}-\mathrm{TC}\left({ }^{125} \mathrm{I}\right)$ and $\left.\left[{ }^{3} \mathrm{H}\right] \mathrm{CEt}\left({ }^{3} \mathrm{H}\right]\right)$ were analyzed, and plasma FCRs for ${ }^{125}-\mathrm{TC}$ and [ $\left.{ }^{3} \mathrm{H}\right] \mathrm{CEt}$ were calculated. The difference in plasma FCRs between $\left[{ }^{3} \mathrm{H}\right] \mathrm{CEt}$ and ${ }^{125}$-TC was calculated. Twenty-four hours after tracer injection, the animals were euthanized, and tissues were analyzed for both tracers. (B) Liver, (C) adrenal gland, and (D) kidney organ FCRs for ${ }^{125} \mathrm{I}-\mathrm{TC}\left({ }^{125} \mathrm{I}\right)$ and $\left[{ }^{3} \mathrm{H}\right] \mathrm{CEt}\left(\left[{ }^{3} \mathrm{H}\right]\right)$. The difference in organ FCRs between $\left[{ }^{3} \mathrm{H}\right] \mathrm{CEt}$ and $\left.{ }^{125} \mathrm{I}-\mathrm{TC}\left({ }^{3} \mathrm{H}\right] \mathrm{CEt}-{ }^{125} \mathrm{I}-\mathrm{TC}\right)$ was calculated. All calculations were done as described in Methods. $n=7$ control mice; $n=5 \mathrm{~L}$-Fox01,3,4 mice. An independent experiment yielded qualitatively identical results. ${ }^{* *} P<0.01$, ${ }^{* *} P<0.001$, and ${ }^{* * *} P \leq 0.0001$, by Student's $t$ test. No significant differences between genotypes were detected in adrenal glands. Data are presented as the mean \pm SEM.

HDL metabolism in L-FoxO1,3,4 and control mice. To address HDL metabolism in more detail, we investigated the turnover of ${ }^{125} \mathrm{I}$-tyramine cellobiose-WT-HDL and $\left[{ }^{3} \mathrm{H}\right]$ cholesteryl hexadecyl ether-WT-HDL $\left({ }^{125} \mathrm{I}-\mathrm{TC}-/\left[{ }^{3} \mathrm{H}\right] \mathrm{CEt}-\mathrm{WT}-\mathrm{HDL}\right)$ in control and L-FoxO1,3,4 mice on a chow diet (Figures 3 and 4) or a WTD (Supplemental Figures 3 and 4). We injected this murine HDL preparation i.v. into mice and then harvested blood samples periodically during a 24-hour period (15). In these studies, $\left.{ }^{3} \mathrm{H}\right] \mathrm{CEt}$ traces the clearance of HDL-associated CE, and ${ }^{125} \mathrm{I}-\mathrm{TC}$ traces the clearance of HDL holoparticles (36). The difference between both tracers $\left(\left[{ }^{3} \mathrm{H}\right]\right.$ CEt- ${ }^{125} \mathrm{I}-\mathrm{TC}$ ) represents selective CE removal from HDL particles.

In control mice on chow, the plasma decay of HDL-associated $\left[{ }^{3} \mathrm{H}\right] \mathrm{CEt}$ was faster than for ${ }^{125} \mathrm{I}-\mathrm{TC}$ (Figure $3 \mathrm{~A}$ ), indicating selective CE removal from the HDL plasma pool by tissues. In L-FoxO1,3,4 mice on chow, the plasma decay of ${ }^{125} \mathrm{I}$-TC was similar to that of control mice (Figure 3B). However, removal of HDL-associated $\left[{ }^{3} \mathrm{H}\right] \mathrm{CEt}$ from plasma was slower in L-FoxO1,3,4 mice than in controls. Similarly, selective CE removal from the HDL plasma pool was also slower in WTD-fed L-FoxO1,3,4 mice compared with littermate controls (Supplemental Figure 3, A and B). Thus, selective CE removal from HDL was markedly reduced in both chowfed and WTD-fed L-FoxO1,3,4 mice. These results suggest that selective CE removal from the HDL plasma pool is substantially reduced in mice lacking hepatic FoxOs.
From the decay curves shown in Figure 3, A and B, and Supplemental Figure 3, A and B, we calculated the plasma fractional catabolic rate (FCR) for both HDL-associated tracers in mice on chow (Figure 4A) or a WTD (Supplemental Figure 4A) (37). In control mice, the plasma FCR for HDL-associated $\left[{ }^{3} \mathrm{H}\right] \mathrm{CEt}$ was substantially higher than for ${ }^{125} \mathrm{I}-\mathrm{TC}$ as a result of selective $\mathrm{CE}$ removal from plasma by tissues. In chow-fed L-FoxO1,3,4 mice, we detected no significant difference in the plasma FCR for ${ }^{125}$ I-TC compared with that in control mice, although in WTD-fed L-FoxO1,3,4 mice, there was a slight decrease in ${ }^{125} \mathrm{I}$-TC decay compared with littermate controls. However, on both diets, compared with control mice, we observed a significant reduction in the plasma FCR for $\left[{ }^{3} \mathrm{H}\right] \mathrm{CEt}(P=0.0046$ and $P=0.031$ for chow and WTD, respectively), yielding a significantly reduced rate of selective CE removal from plasma in L-FoxO1,3,4 mice $(P=0.0001$ and $P=0.046$ for chow and WTD, respectively). This shows that there is reduced selective CE clearance from the plasma HDL pool by tissues in L-FoxO1,3,4 mice.

Next, we investigated HDL metabolism by defined organs. Twenty-four hours after ${ }^{125} \mathrm{I}-\mathrm{TC}-/\left[{ }^{3} \mathrm{H}\right] \mathrm{CEt}-\mathrm{WT}$-HDL injection, we analyzed the tracer content of tissues and calculated HDL uptake in terms of the organ FCR (15). In control mice on either diet, the hepatic organ FCR showed a selective HDL-CE uptake by the liver (Figure 4B and Supplemental Figure 4B) that was in line with earli- 
Table 1. HDL metabolism of L-Fox01,3,4 mice

\begin{tabular}{|c|c|c|c|c|c|c|c|}
\hline & & \multicolumn{3}{|c|}{$\begin{array}{l}\text { Control mice } \\
\text { Chow }\end{array}$} & \multicolumn{3}{|c|}{$\begin{array}{c}\text { L-Fox01,3,4 mice } \\
\text { Chow }\end{array}$} \\
\hline & & 125 & [ $\left.{ }^{3} \mathrm{H}\right]$ & {$\left[{ }^{3} \mathrm{H}\right]-{ }^{125}$} & 125 & {$\left[{ }^{3} \mathrm{H}\right]$} & {$\left[{ }^{3} \mathrm{H}\right]-{ }^{-125}$} \\
\hline Plasma FCRs $\times \mathrm{h}^{-1}$ & & $0.052 \pm 0.008$ & $0.133 \pm 0.011$ & $0.0811 \pm 0.006$ & $0.049 \pm 0.003$ & $0.0844 \pm 0.007^{\AA}$ & $0.0354 \pm 0.004^{A}$ \\
\hline \multirow{3}{*}{ Organ FCRs $\times h^{-1} \times 10^{3}$} & Stomach & $1.90 \pm 0.23$ & $1.27 \pm 0.24$ & & $1.01 \pm 0.14^{A}$ & $0.348 \pm 0.060^{\AA}$ & \\
\hline & Intestine & $7.3 \pm 1.2$ & $4.0 \pm 0.52$ & & $7.5 \pm 0.7$ & $2.5 \pm 0.27^{A}$ & \\
\hline & Carcass & $27.4 \pm 4.3$ & $25.4 \pm 2.5$ & & $24.8 \pm 1.4$ & $18.6 \pm 1.3^{A}$ & \\
\hline
\end{tabular}

Data show plasma FCRs and tracer uptake rates by tissues for ${ }^{125} /$-TC- $/\left[{ }^{3} \mathrm{H}\right] \mathrm{CEt}-\mathrm{WT}-\mathrm{HDL}$ in chow-fed L-Fox01,3,4 mice. ${ }^{125}$-TC-/[ $\left.{ }^{3} \mathrm{H}\right] \mathrm{CEt}-\mathrm{WT}-\mathrm{HDL}$ was injected i.v. into chow-fed L-Fox01,3,4 mice and littermate controls. During the subsequent 24-hour period, blood was harvested periodically to determine the plasma decay of both tracers. ${ }^{125} \mathrm{I}-\mathrm{TC}\left({ }^{125} \mathrm{I}\right)$ and $\left[{ }^{3} \mathrm{H}\right] \mathrm{CEt}\left(\left[{ }^{3} \mathrm{H}\right]\right)$ were analyzed, and plasma FCRs for ${ }^{125} \mathrm{I}-\mathrm{TC}$ and $\left[{ }^{3} \mathrm{H}\right] \mathrm{CEt}$ were calculated. The difference in plasma FCRs between $\left[{ }^{3} \mathrm{H}\right] \mathrm{CEt}$ and ${ }^{125}$-TC was calculated. Twenty-four hours after tracer injection, the animals were euthanized, and tissues were analyzed for both tracers. Splenic, stomach, intestinal, heart, lung, and carcass organ FCRs for $\left.{ }^{125}-\mathrm{TC}\left({ }^{125} \mathrm{I}\right),{ }^{3} \mathrm{H}\right] \mathrm{CEt}\left(\left[{ }^{3} \mathrm{H}\right]\right)$ and the difference in organ FCRs between $\left[{ }^{3} \mathrm{H}\right] \mathrm{CEt}$ and ${ }^{125} \mathrm{I}-\mathrm{TC}\left(\left[{ }^{3} \mathrm{H}\right] \mathrm{CEt}-{ }^{125} \mathrm{I}-\mathrm{TC}\right)$ were calculated. All calculations were done as described in Methods. For control mice, values represent the mean $\pm \mathrm{SEM}$. $n=7$ control mice and $n=5 \mathrm{~L}-\mathrm{Fox} 01,3,4$ mice. An independent experiment yielded qualitatively identical results. ${ }^{A} P<0.05$, by Student's $t$ test.

er studies in WT mice $(26,38)$. In L-FoxO1,3,4 mice on either diet, the hepatic uptake rate for ${ }^{125} \mathrm{I}$-TC was similar to that of control mice. However, the hepatic organ FCR for $\left[{ }^{3} \mathrm{H}\right] \mathrm{CEt}(P=0.0035$ and $P=0.011$ for chow and WTD, respectively) and the selective CE uptake from HDL $(P=0.0009$ and 0.009 for chow and WTD, respectively) were decreased significantly compared with control mice on either diet. This indicates that hepatic selective uptake of HDL-CE is defective in L-FoxO1,3,4 mice.

Compared with the liver, the HDL tracer uptake rates were quantitatively low in all nonhepatic tissues. In adrenal glands, which also express SR-BI (16), chow-fed L-FoxO1,3,4 mice showed a trend toward reduced selective CE uptake (Figure 4C). However, we did not observe this trend in WTD-fed L-FoxO1,3,4 mice (Supplemental Figure 4C). We did not expect SR-BI expression to be lower in L-FoxO1,3,4 adrenal glands, because this is a hepatocyte-specific FoxO-knockout mouse model. Indeed, we observed no change in Scarb1 or Foxo1 gene expression levels in L-FoxO1,3,4 adrenal glands (Supplemental Figure 5). However, because HL is a secreted protein that is known to function in SR-BI-mediated uptake of HDL-C, we speculate that the low HL activity of L-FoxO1,3,4 mice could potentially contribute to the trend of lower selective CE uptake in other SR-BI-expressing tissues (such as adrenal gland) in chow diet conditions. In the kidneys, which do not express SR-BI, organ FCRs for either HDL-associated tracer did not differ between control and L-FoxO1,3,4 mice on either chow or a WTD (Figure 4D and Supplemental Figure 4D). However, consistent with previous studies, kidney organ FCRs for HDL-associated ${ }^{125} \mathrm{I}$-TC were higher than for HDL-associated $\left[{ }^{3} \mathrm{H}\right]$ CEt, which reflects a preferential renal catabolism of HDL apolipoproteins (26). In spleen, stomach, intestine, and carcass, the organ FCRs for HDL-associated $\left[{ }^{3} \mathrm{H}\right] \mathrm{CEt}$ were decreased in chowfed L-FoxO1,3,4 mice compared with controls (Table 1). Of these tissues, only the spleen showed selective uptake.

HDL metabolism in primary murine hepatocytes. Next, we evaluated HDL-CE uptake into isolated primary hepatocytes from control and L-FoxO1,3,4 mice in a dose-response experiment.
Following a 4-hour seeding period, we incubated hepatocytes in medium containing ${ }^{125} \mathrm{I}-\mathrm{TC}-/\left[{ }^{3} \mathrm{H}\right] \mathrm{CEt}-W T-H D L$ at $10,20,40$, or $100 \mu \mathrm{g}$ HDL protein/ml for 2 hours. In control hepatocytes, $\left[{ }^{3} \mathrm{H}\right]$ CEt uptake was substantially higher than for ${ }^{125} \mathrm{I}-\mathrm{TC}$ at all doses, indicating selective CE uptake from HDL (Figure 5A). This observation is in line with previous results $(26,39)$. In L-FoxO1,3,4 hepatocytes, ${ }^{125} \mathrm{I}$-TC uptake was similar to that of controls (Figure 5B). However, $\left[{ }^{3} \mathrm{H}\right] \mathrm{CEt}$ uptake was significantly decreased compared with that of control cells at all doses, yielding a decrease of approximately $50 \%$ in selective CE uptake from HDL. We also measured HDL-CE uptake over a 2-hour time course at 20 $\mu \mathrm{g}$ HDL protein/ml (Supplemental Figure 6, A and B). At all time points, selective HDL-CE uptake was significantly reduced by approximately $40 \%$ in L-FoxO1,3,4 hepatocytes compared with HDL-CE uptake in controls. Western blot analysis confirmed that SR-BI protein levels were substantially decreased in L-FoxO1,3,4 hepatocytes compared with levels in controls (Figure 5C). We also observed significantly lower expression levels of Scarb1 and Lipc mRNA in L-FoxO1,3,4 hepatocytes (Figure 5D). However, we noted that the mRNA of both genes declined over time after hepatocyte isolation, especially in WT hepatocytes, as was previously observed (40). Taken together, these experiments demonstrate that selective $\mathrm{CE}$ uptake from HDL is decreased in FoxO-deficient hepatocytes in a cell-autonomous manner.

Rescuing SR-BI reverses the accumulation of $H D L-C$ in $L$-FoxO1,3,4 mice. To determine whether SR-BI induction in the livers of FoxO-deficient mice can reverse the HDL-C phenotype, we transduced WTD-fed L-FoxO1,3,4 mice and littermate controls with an adenovirus expressing SR-BI (Ad.SR-BI). We titrated the virus to a low dose to achieve only mild increases in SR-BI, because several-fold overexpression in WT mice is known to potently reduce HDL-C, irrespective of the HDL subclass (13). Three days after virus injection, we measured SR-BI expression levels. As a result of the low titer we used, we detected no increases in total SR-BI levels in control mice transduced with Ad.SR-BI compared with those transduced with a control virus (Ad.GFP) (Figure 6A). 
A

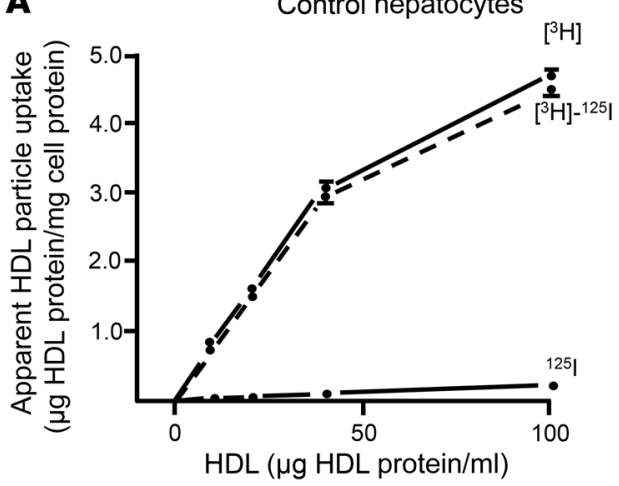

B

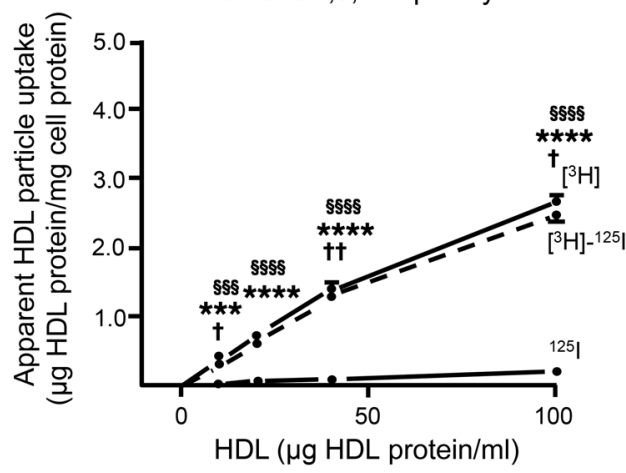

C

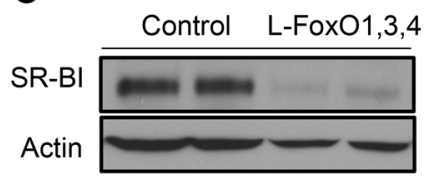

D

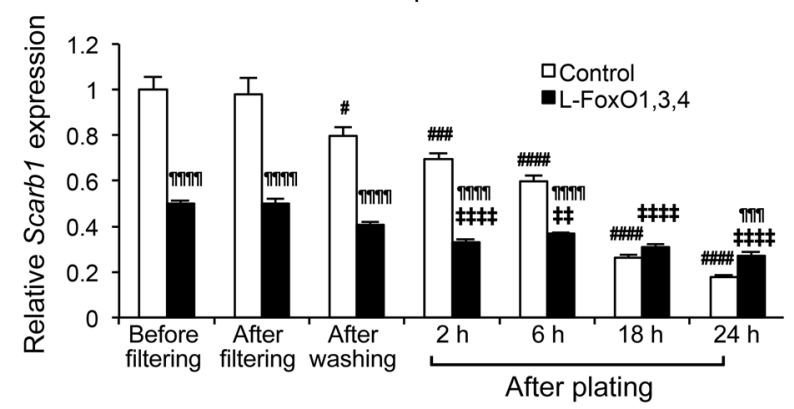

Scarb1 expression

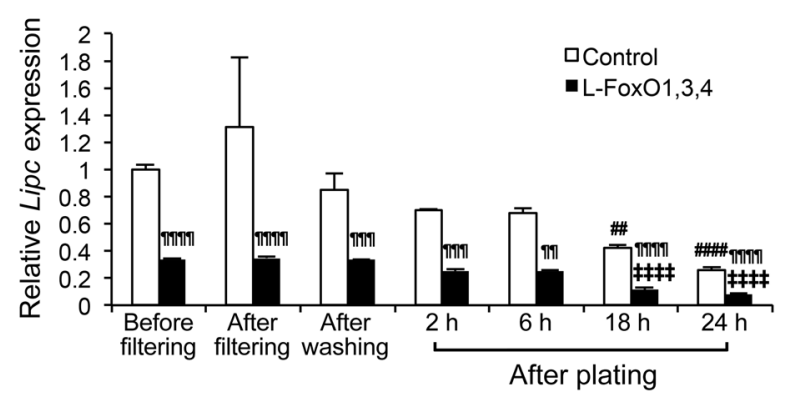

Figure 5. Uptake of ${ }^{125} \mathrm{I}-\mathrm{TC}-/\left[{ }^{3} \mathrm{H}\right] \mathrm{CEt}-\mathrm{WT}-\mathrm{HDL}$ by hepatocytes isolated from chow-fed L-Fox01,3,4 mice. (A and B) Hepatocytes from chow-fed L-FoxO1,3,4 mice and littermate controls were incubated ( $37^{\circ} \mathrm{C}, 2$ hours) in medium containing ${ }^{125} \mathrm{I}-\mathrm{TC}-/\left[{ }^{3} \mathrm{H}\right] \mathrm{CEt}-\mathrm{WT}-\mathrm{HDL}(10,20,40$, or $100 \mu \mathrm{g} \mathrm{HDL}$ protein/mI). Finally, cells were harvested, and apparent HDL particle uptake was analyzed as outlined in Methods. Values represent the mean of $(\mathbf{A}) n=3$ (control) and $(\mathbf{B}) n=3$ $(\mathrm{L}-$ Fox01,3,4) independent determinations. An independent similar experiment yielded qualitatively identical results. Where no error bars are visible, the SEM was smaller than the symbol. (C) Western blots of SR-BI in primary hepatocytes from L-Fox01,3,4 mice and littermate controls. Representative bands are shown. Two independent experiments yielded qualitatively identical results. (D) Relative Scarb1 and Lipc expression by qPCR in hepatocytes from chow-fed L-Fox01,3,4 mice and littermate controls at different stages of the cell isolation procedure (see Methods). (A and $\mathbf{B}) \$ \S \$<0.001$ and $\$ \$ \S \$<0.0001$, comparing $\left[{ }^{3} \mathrm{H}\right]$ CEt between L-Fox01,3,4 and control hepatocytes; ${ }^{* *} P<0.001$ and ${ }^{* * * *} P<0.0001$, comparing [ $\left.{ }^{3} \mathrm{H}\right] \mathrm{CEt}-{ }^{125}$ I-TC between L-FoxO1,3,4 and control hepato-

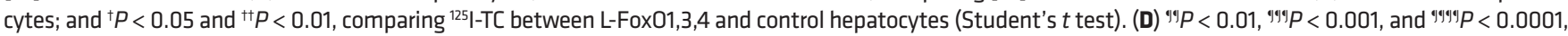

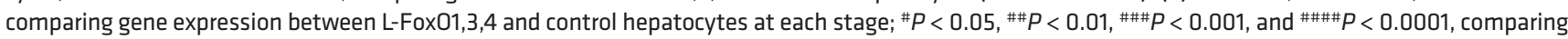
gene expression between control hepatocytes at baseline (before filtering) and control hepatocytes at each stage; and ${ }^{\ddagger \neq} P<0.01$ and ${ }^{\ddagger \neq \neq \ddagger ~} P<0.0001$, comparing gene expression between L-Fox01,3,4 hepatocytes at baseline (before filtering) and L-FoxO1,3,4 hepatocytes at each stage (2-way ANOVA, followed by Tukey's post hoc test). All data are presented as the mean \pm SEM.

However, L-FoxO1,3,4 mice injected with Ad.SR-BI showed a 5 -fold increase in liver SR-BI compared with those injected with Ad.GFP. We noted that even after this 5-fold increase, the levels of SR-BI were still about half as much as those in littermate control mice. Transducing L-FoxO1,3,4 mice with SR-BI caused a substantial normalization of the HDL-C accumulation (Figure 6B). Western blots confirmed that the leftward shifts of apoA-I and apoE were also normalized (Figure 6C, compare lanes 10 and 11 with lanes 4 and 5). Corresponding to the finding that the WT control mice transduced with this low-titer Ad.SR-BI showed no overexpression of SR-BI, we detected no decrease in HDL-C in these mice. Neither Lipc mRNA expression nor plasma HL activity was affected by Ad.SR-BI transduction (Supplemental Figure 7, A and B). Collectively, these findings demonstrate that rescuing SR-BI expression in hepatic FoxO-deficient mice is sufficient to reverse the accumulation of cholesterol in large HDL particles.

Acute depletion of hepatic FoxOs is sufficient to induce the HDL phenotype. We predicted that $S c a r b 1$ and Lipc are transcriptional targets of FoxOs, because (a) the mRNA expression of these genes was low in every condition tested; (b) motif analysis using HOMER (Hypergeometric Optimization of Motif EnRichment) software (41) identified dozens of FoxO consensus sequences in and near Scarb1 and Lipc (Supplemental Figure 8, A-C); and (c) publically available microarrays are consistent with this, showing that transgenic overexpression of constitutively active FoxOs causes elevated liver expression of Scarb1 mRNA (11). Moreover, mice lacking the proteins insulin receptor substrates 1 and 2 (Irs1 and Irs2), which are expected to have constitutively active FoxOs, have elevated liver expression of Scarb1 and reduced serum HDL-C levels. Importantly, concomitant knockout of FoxO1 with Irs1 and Irs2 partially normalizes this phenotype (5).

To further validate the notion that decreases in Scarb1 and Lipc are directly due to FoxO depletion, and not compensatory defects due to long-term genetic loss of FoxOs, we transduced chow-fed, adult Foxo $1^{f / f l}$, Foxo $3^{f / f l}$, and Foxo $4^{f / Y}$ control mice with an adenoassociated virus expressing Cre under a hepatocyte-specific promoter (AAV8.Tbg.Cre). Two weeks after the injection, we found that chow-fed, triple-floxed mice transduced with AAV8.Tbg.Cre virus started to accumulate cholesterol in large HDL fractions 
A

\begin{tabular}{|c|c|c|c|c|}
\hline & \multicolumn{2}{|c|}{ Control - WTD } & \multicolumn{2}{|c|}{ L-FoxO1,3,4 - WTD } \\
\hline Virus & Ad.GFP & Ad.SR-BI & Ad.GFP & Ad.SR-BI \\
\hline $\begin{array}{l}\text { SR-BII } \\
\text { actin }\end{array}$ & $1.00 \pm 0.09$ & $1.16 \pm 0.09$ & $0.11 \pm 0.05$ & $\overline{0.55 \pm 0.05}$ \\
\hline SR-BI & c- & - & & -- \\
\hline Actin & - & 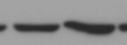 & & \\
\hline
\end{tabular}

B

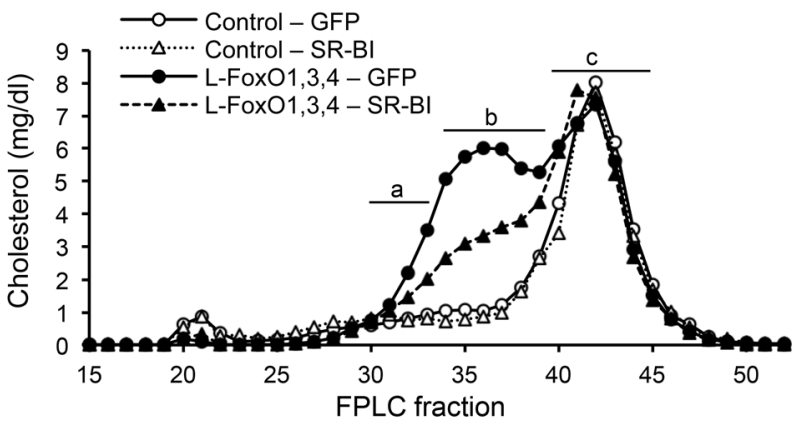

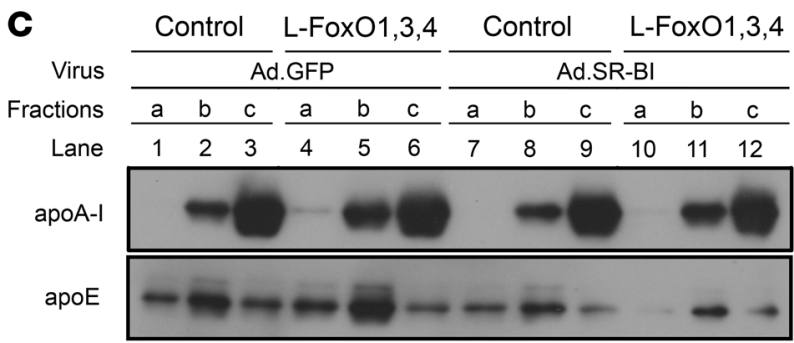

(Supplemental Figure 9). Four weeks after virus injection, we euthanized the mice, at which point the HDL-C accumulation phenotype was exacerbated compared with what was observed at the 2-week time point (Figure 7A). We verified that AAV8.Tbg.Cre caused FoxO depletion, as well as low levels of G6pcand high levels of Gck, two known targets of FoxO transcriptional activation and repression, respectively (9) (Figure 7B). Moreover, it caused decreases in Scarb1 and Lipc mRNA levels as well as SR-BI protein levels (Figure 7C). The levels of Scarb1 and Lipc mRNA were significantly correlated with the level of FoxO1 knockdown (Figure 7D).

Finally, we also measured protein expression levels of PDZK1 in L-FoxO1,3,4 liver lysates and primary hepatocytes. PDZK1 is a scaffold protein that is essential for SR-BI stability and localization in hepatocytes and has been reported to posttranscriptionally regulate SR-BI levels $(42,43)$. We found that in L-FoxO1,3,4 liver lysates and primary hepatocytes, there were no changes in PDZK1 expression levels between L-FoxO1,3,4 and the matched controls (Supplemental Figure 10). Thus, we have no evidence for posttranslational regulation of SR-BI by FoxOs. Taken together, these data support a model in which FoxOs acutely regulate Scarb1 and Lipc at the transcriptional level, thus affecting HDL-C levels and HDL-mediated reverse cholesterol transport.

\section{Discussion}

Here, we report that hepatic FoxOs are required for normal hepatic clearance of HDL-C. Our results suggest that hepatic FoxOs promote the expression of SR-BI and HL, which induce HDL-C
Figure 6. Ad.SR-BI in WTD-fed L-Fox01,3,4 mice. (A) Western blot of hepatic SR-BI expression in WTD-fed L-Fox01,3,4 mice and littermate controls transduced with Ad.SR-BI or Ad.GFP control virus. SR-BI/actin denotes relative SR-BI expression levels by densitometric scanning $(n=$ 2-4). (B) Cholesterol levels in plasma fractionated by FPLC in the same mice as in A. (C) Western blots of plasma apoA-I and apoE in fractionated plasma obtained from FPLC in B. Lanes a, b, and c correspond to pooled fractions $30-33,34-39$, and $40-45$, respectively.

uptake from the plasma into the liver. This mechanism demonstrates the importance of these insulin-inactivated transcription factors in regulating HDL-C metabolism.

SR-BI and HL are both important for plasma HDL-C turnover. Both SR-BI- and HL-knockout mice have elevated plasma cholesterol levels and cholesterol accumulation in large HDL particles $(14,28)$ due to impaired selective uptake of HDL-CE by the liver $(26,27)$. Some studies have suggested that SR-BI and HL promote selective uptake by acting together (44), although others indicate that the two act through independent mechanisms (24). Evidence in humans also shows important roles for SR-BI and HL in HDL-C metabolism. In GWAS, variants near both Scarb1 and Lipc have been associated with HDL-C (45-47). Furthermore, individuals with HL deficiency were reported to have an accumulation of large, buoyant plasma HDL particles (48-50). Thus, mechanisms regulating HDL-C clearance through these 2 proteins may be relevant across species.

Hepatic FoxOs have also been shown to control other downstream aspects of hepatic cholesterol metabolism. Once HDL-CE enters the hepatocyte, it can be stored, secreted on lipoproteins, or excreted into the bile. There are 2 possible mechanisms to allow for cholesterol excretion into the bile. The first mechanism involves the secretion of cholesterol directly into the bile via the heterodimeric cholesterol transporters $A b c g 5$ and $A b c g 8(51,52)$. The second mechanism involves the conversion of cholesterol into bile acids through a series of enzymatic reactions, in which Cyp7a1 encodes the rate-limiting enzyme $(53,54)$. All 3 genes $-A b c g 5$, $A b c g 8$, and Cyp7a1 - are reportedly regulated by hepatic FoxO1 (55-58). Moreover, we have previously reported that an additional enzyme involved in bile acid synthesis, Cyp8b1, is a FoxO1 target (10). Our current findings that hepatic FoxOs also regulate clearance of HDL-C by the liver indicate that FoxOs have pleiotropic effects on hepatic cholesterol homeostasis.

The inactivation of hepatic FoxOs by insulin signaling has been well characterized $(1,59)$. Several experimental mouse models have shown that ablating the upstream FoxO regulators involved in this insulin signaling cascade (e.g., the insulin receptor, insulin receptor substrate proteins, or Akt) leads to impaired glucose homeostasis as a result of constitutive FoxO activation (4, 5, 60, 61). Thus, these models may also provide insight into the regulation of HDL-C levels via the insulin/FoxO pathway. For instance, liver ablation of the insulin receptor in mice causes decreased serum HDL-C associated with a reduction in large, apoE-containing HDL particles (60). Likewise, Irs1 and Irs2 double-knockout mice have elevated Scarb1 mRNA levels and reduced serum HDL-C, whereas concomitant knockout of FoxO1 with Irs1 and Irs2 partially reverses this (5). Furthermore, transgenic overexpression of constitutively active FoxOs increases liver Scarb1 mRNA levels (11). These data 
A

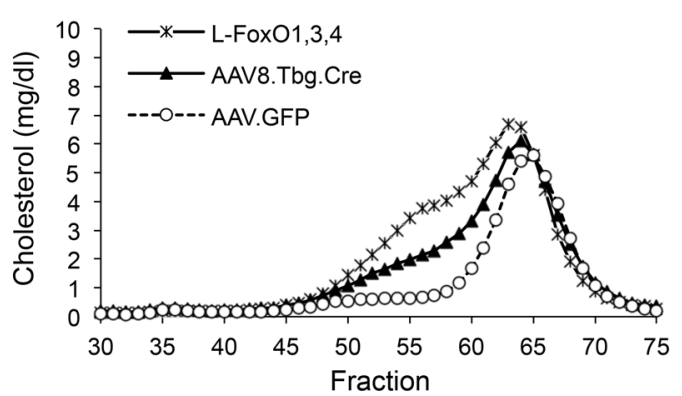

C

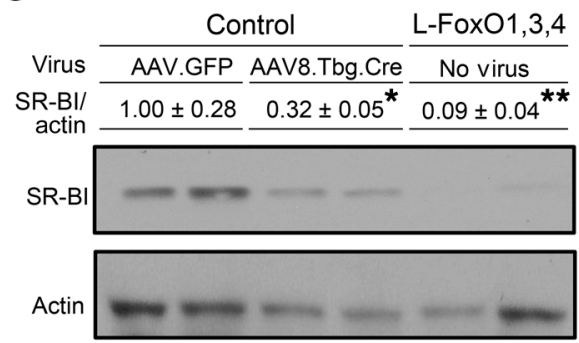

B
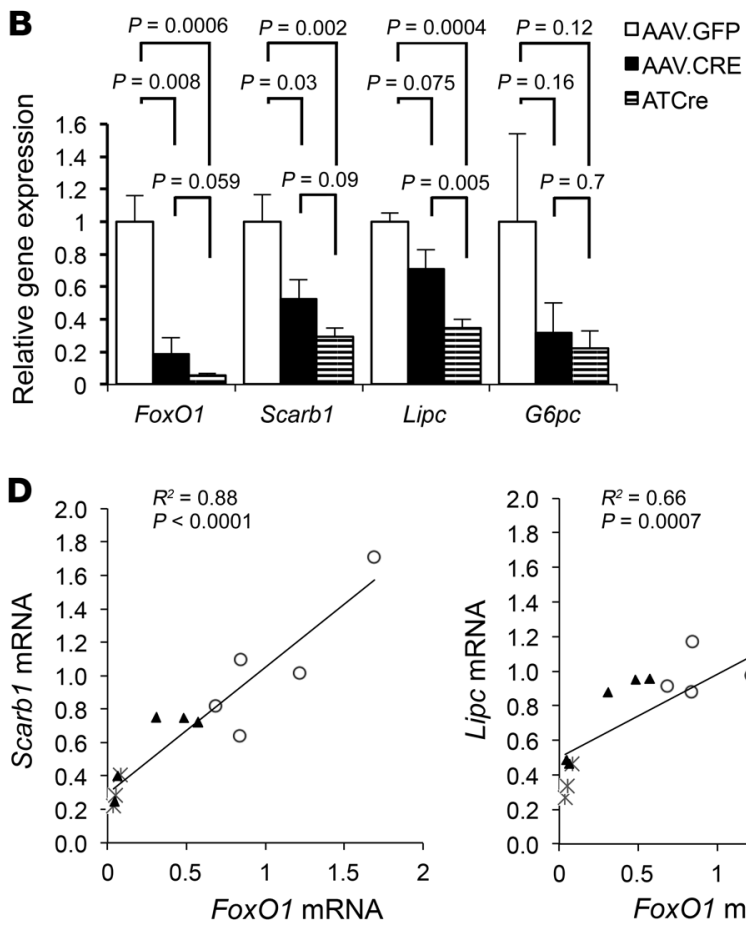

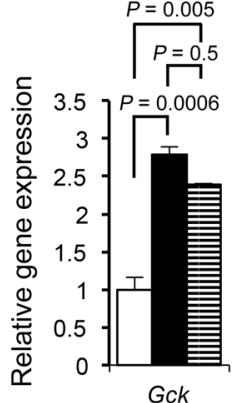

AAV.GFP $\triangle$ AAV8.Tbg.Cre * L-FoxO1,3,4

Figure 7. Acute knockdown via Cre adeno-associated virus in chow-fed hepatic FoxO-floxed mice. (A-D) Chow-fed, adult Foxo $1^{f / f f l}$, Foxo $3^{f / f f l}$, and Foxo $4^{f / / \gamma}$ control mice transduced with adeno-associated virus (serotype 8) expressing Cre recombinase driven by the hepatocyte-specific Tbg promoter (AAV8.Tbg. Cre) or control virus (AAV.GFP) $(n=5)$. For comparison, we also included a group of traditional L-FoxO1,3,4-knockout mice that were not transduced with virus, but rather had FoxO deficiency since birth $(n=4)$. Four weeks after virus transduction, mice were fasted for five hours, and then plasma and livers were collected. (A) Cholesterol levels in plasma fractionated by FPLC 4 weeks after virus transduction. (B) Relative hepatic gene expression by qPCR. (C) Representative Western blot of hepatic SR-BI expression. SR-BI/actin denotes relative SR-BI expression levels by densitometric scanning. ${ }^{*} P<0.05$ and ${ }^{*} P<0.01$ versus AAV.GFP mice. No significant difference was detected between AAV8.Tbg.Cre mice and L-Fox01,3,4 mice. (D) Correlation between Scarb1 or Lipc mRNA and FoxO1 mRNA. The $P$ values in B and $\mathbf{C}$ were calculated by 1-way ANOVA, followed by a post hoc $t$ test using the pooled SD, without Bonferroni's correction. Data are presented as the mean \pm SEM.

provide additional evidence to suggest that hepatic FoxOs directly mediate the effect of insulin on HDL-C metabolism through their transcriptional effects on Scarb1 and Lipc.

We propose that the regulation of HDL-C uptake by FoxOs is part of a larger program of hepatic insulin regulation of cholesterol metabolism. In addition to what is uncovered in the present work, liver insulin signaling is also known to positively regulate the Srebp2 pathway (60) and the levels of the LDL receptor (62) and negatively regulate the catabolism of cholesterol into bile acids (63), biliary cholesterol excretion (55), and bile acid composition (10). It has been proposed that fatty acid and cholesterol metabolism is regulated by nutrient status in order to coordinate (a) the supply of cellular membrane components, and (b) the usage of available precursor molecules (64). As insulin is a key regulator of the nutrient-rich state, it is possible that its actions coordinate glucose, fatty acid, and cholesterol flux to maintain overall energy homeostasis.

Given the well-known role of FoxOs in promoting hepatic glucose production (65), our findings suggest a potential connection between plasma glucose and plasma HDL-C in the setting of type 2 diabetes. Patients with type 2 diabetes have elevated plasma glucose, along with reduced plasma HDL-C (66). As excessive FoxO activity is expected to contribute to high hepatic glucose production in these patients (65), perhaps it also contributes to their low HDL-C. Indeed, HL, one of the FoxO targets we identified, is known to have increased activity in patients with type 2 diabetes $(67,68)$. Hence, it is possible that elevated FoxO activity in the setting of type 2 diabetes leads to more rapid HDL-C turnover.

It is of interest that L-FoxO1,3,4 mice accumulated cholesterol preferentially in large, apoE-rich HDL particles, while the amount of cholesterol on "traditional-sized" HDL remained unchanged among the genotypes. It has been reported that apoE facilitates the uptake of HDL-CE via SR-BI in vivo (69). Moreover, apoE-containing HDL may be a preferred substrate for HL $(70,71)$. Therefore, it is possible that these preferences of SR-BI and HL may contribute to the specific accumulation of apoE-containing HDL in L-FoxO1,3,4 mice. We also observed that the difference in HDL-C between genotypes was exacerbated on the WTD, despite the fact that HL was halved and SR-BI was exceedingly low in L-FoxO1,3,4 mice on either diet. What is the cause of this HDL-C exacerbation? Interestingly, SR-BI-knockout mice also showed the same exacerbation: differences in HDL-C between SR-BI-knockout mice and controls were greater after Western diet feeding than after chow diet feeding (72). Thus the exacerbation was independent of additional SR-BI lowering. We speculate that multiple factors may be involved, including changes in the particles themselves. Some of these may include alterations in other HDL lipid species or HDLbound proteins, or a potential increased competition for clearance of apoE-rich HDL particles via the alternative pathway of LDLR/ 
LRP1/HSPG (in other words, Western diet-induced increases in apoB-containing particles may compete with apoE-rich HDL for binding to LDLR/LRP1/HSPG).

In this work, we have revealed a link between the insulin-repressible FoxO transcription factors and HDL-mediated reverse cholesterol transport. This cardioprotective pathway is a critical step for the excretion of cholesterol from the periphery into the feces (73-76). Indeed, patients with a rare loss-of-function variant in the gene encoding SR-BI have significantly increased levels of plasma HDL-C as well as an increased risk of coronary heart disease (47). Thus, further characterization of how the insulin/FoxO pathway regulates reverse cholesterol transport may improve our understanding of the relationships between insulin resistance, diabetes, and atherogenesis and inform clinical decisions about future treatments for diabetes-related cardiovascular disease.

\section{Methods}

Mice and diets. Only 3- to 5-month-old adult male mice were studied. L-FoxO1,3,4 mice have been previously described $(8,9)$. The control used mice included Foxo1 $1^{f l / f l}$, Foxo $3^{f / f l}$, and Foxo ${ }^{f / Y}$ mice that lack liver-specific $\alpha 1$-antitrypsin-Cre. Mice were fed either a standard chow diet (Purina) or a WTD containing $42 \% \mathrm{kcal}$ from fat and $0.2 \%$ cholesterol (TD 88137; Harlan Teklad) for 3 weeks. For the adenovirus experiments, mice were injected i.v. with $1 \times 10^{8}$ virus particles/gram of body weight 3 days prior to sacrifice. Murine SR-BI adenovirus was a gift of Charles M. Rice (The Rockefeller University, New York, New York, USA) (77). For the acute FoxO depletion experiments, mice were injected i.v. with $1 \times 10^{11}$ virus particles/mouse 4 weeks prior to sacrifice. AAV8.Tbg.Cre was a gift of Morris Birnbaum (Perelman School of Medicine, University of Pennsylvania, Philadelphia, Pennsylvania USA). Mice were fasted for 5 hours on the day of sacrifice, when blood and livers were collected for analysis. Mice were maintained on a 12-hour light/12-hour dark cycle, with the dark cycle occurring between 7:00 pm and 7:00 am.

Plasma lipoprotein analysis. Total plasma cholesterol was measured using a commercial colorimetric assay (Wako). Plasma lipoproteins were analyzed by running $200 \mu$ l of pooled plasma onto a FPLC system consisting of 2 Superose 6 columns connected in series (Amersham Pharmacia Biotech) as described previously (78). Fractions for chowfed mice were collected using the fraction collector FC 204 (Gilson), and fractions for WTD-fed mice were collected using the fraction collector FRAC-100 (Pharmacia LKB). For Western blots of fractionated plasma from both chow-fed and WTD-fed mice, $5 \mu$ from each fraction was pooled in pairs and run on a $4 \%-15 \%$ Tris-HCL Gradient Gel (Bio-Rad), with the exception of adenovirus-injected mice, for which $5 \mu \mathrm{l}$ from each fraction was pooled in groups of 4 or 6 , as indicated in Figure 6. Antibodies against apoA-I and apoE were from Meridian Life Science (catalogs K23500R and K23100R, respectively).

Gene expression. Liver RNA was isolated using TRIzol (Invitrogen, Thermo Fisher Scientific). cDNA was synthesized using qScript (QuantaBioSciences), and qPCR was performed using SYBR Green (New England Biolabs). Genes were normalized to $36 \mathrm{~b} 4$. The primer sequences are available in the Supplemental Experimental Procedures.

$S R-B I$ expression and HL activity. Liver lysates were prepared in T-PER Tissue Extraction Buffer (Thermo Fisher Scientific) with an added protease inhibitor cocktail (Roche). The lysates were then immunoblotted for SR-BI (Novus; NB400-104), and $\beta$-actin was used as a loading control (13E5; Cell Signaling Technology; 4970S). For Western blots of SR-BI in primary hepatocytes, cells were isolated and incubated as described previously (79). Plasma HL activity was determined as described previously (34). Briefly, plasma was incubated with $10 \%$ Intralipid/ $\left[{ }^{3} \mathrm{H}\right]$-triolein emulsion (PerkinElmer; NET431L005MC) as a substrate and human serum as the source of apoCII (80). The contribution of HL in the plasma was determined by including $\mathrm{NaCl}$ (final concentration $1 \mathrm{M}$ ) (81). Because heparin was not administered to mice prior to blood collection, the lipase activity was primarily HL (35).

Radiolabeling of HDL. HDL was prepared from WT mice that were fasted for 4 hours before blood harvest. Murine WT-HDL (density = $1.063-1.21 \mathrm{~g} / \mathrm{ml}$ ) was isolated from plasma by sequential ultracentrifugation (82). Murine WT-HDL was double labeled with ${ }^{125} \mathrm{I}-\mathrm{TC}$ in the apolipoprotein moiety and with $\left.{ }^{3} \mathrm{H}\right] \mathrm{CEt}$ (PerkinElmer - NET$859001 \mathrm{MC})$ in the CE moiety $\left.(26,83) .{ }^{3} \mathrm{H}\right] \mathrm{CEt}$ was introduced into ${ }^{125} \mathrm{I}-\mathrm{TC}-\mathrm{WT}-\mathrm{HDL}$ by exchange from donor liposomal particles, which contained $\left[{ }^{3} \mathrm{H}\right] \mathrm{CEt}$, using human plasma CE transfer protein (84). The final ${ }^{125} \mathrm{I}-\mathrm{TC}-/\left[{ }^{3} \mathrm{H}\right] \mathrm{CEt}-\mathrm{WT}-\mathrm{HDL}$ preparation was extensively dialyzed against PBS ( $\left.\mathrm{pH} 7.4,4^{\circ} \mathrm{C}\right)$ containing EDTA $(1 \mathrm{mM})$.

HDL metabolism in mice. For plasma decay analysis of radiolabeled WT-HDL, mice were fasted for 4 hours before tracer injection (15). Then, ${ }^{125} \mathrm{I}-\mathrm{TC}-/\left[{ }^{3} \mathrm{H}\right] \mathrm{CEt}-\mathrm{WT}-\mathrm{HDL}(30 \mu \mathrm{g}$ protein/mouse) was injected via the tail vein, and thereafter, blood samples ( $30 \mu \mathrm{l} /$ time point) were collected periodically (10 minutes, 30 minutes, 2 hours, 7 hours, 22 hours, and 24 hours) after injection. Animals were fasted throughout the 24-hour study period but had unlimited access to water. Plasma aliquots were directly assayed for ${ }^{125} \mathrm{I}$ radioactivity, and $\left[{ }^{3} \mathrm{H}\right]$ was analyzed after lipid extraction (85). Computer modeling was used to fit (by the method of least squares) multiexponential curves, arising from a common 2-pool model, simultaneously to both tracers' plasma decay data and to calculate plasma FCRs for each tracer (86). The modeling was done separately for the data from each mouse, so that individual plasma FCRs for both tracers were calculated for each animal.

Tissue sites of uptake of HDL-associated tracers were determined 24 hours after injection of radiolabeled WT-HDL (15). Finally, animals were deeply anesthetized, the abdomen and chest were opened, and a catheter was inserted into the right heart. The inferior vena cava was cut, and the mice were perfused extensively with saline $(50 \mathrm{ml} /$ animal). After perfusion, liver, adrenal glands, kidneys, heart, lungs, spleen, stomach, intestine, and carcass from each mouse were harvested and homogenized. Homogenates from each tissue and from carcass were directly assayed for ${ }^{125}$ I radioactivity, and aliquots were analyzed in parallel for $\left[{ }^{3} \mathrm{H}\right]$ after lipid extraction (85).

Total radioactivity recovered from all tissues and from the carcass of each mouse was calculated (15). The fraction of total tracer uptake attributed to a specific organ was calculated as the radioactivity recovered in that organ divided by the total radioactivity recovered from all tissues and carcass. Thus, the percentage of recovered extravascular radioactivity in tissues was determined 24 hours after injection of labeled HDL.

To allow comparison of the specific activities of various tissues in HDL internalization and to directly compare the rates of uptake of the apolipoprotein component and the CE moiety of HDL, the data are expressed as organ FCRs (15). These rates were calculated as follows: $($ organ FCR in tissue $\mathrm{X})=($ plasma FCR $) \times($ fraction [\%] of total body tracer recovery in tissue $\mathrm{X}$ ). This organ FCR represents the fraction of the plasma pool of either HDL tracer cleared by an organ per hour. 
${ }^{125}$ I-TC represents the uptake of HDL holoparticles by tissues (36). Selective HDL-CE uptake was calculated as the difference in organ FCR between $\left[{ }^{3} \mathrm{H}\right] \mathrm{CEt}$ and ${ }^{125} \mathrm{I}$-TC.

Preparation of murine hepatocytes. Primary hepatocytes were isolated from murine liver by perfusion $\left(37^{\circ} \mathrm{C}, 18\right.$ minutes) with HBSS supplemented with collagenase $(0.3 \mathrm{mg} / \mathrm{ml}$, type I), HEPES (10 mM), and protease inhibitor mixture "complete" (87). Thereafter, these cells were seeded $\left(37^{\circ} \mathrm{C}, 4\right.$ hours) in DMEM containing FBS $(5 \%, v / v)$, penicillin $(100 \mu \mathrm{g} / \mathrm{ml})$, and streptomycin $(100 \mu \mathrm{g} / \mathrm{ml})$. Finally, the culture medium was aspirated, and the cells were washed 3 times in PBS. Hepatocytes were used for ${ }^{125} \mathrm{I}-\mathrm{TC}-/\left[{ }^{3} \mathrm{H}\right] \mathrm{CEt}-\mathrm{WT}$-HDL uptake assays. For the time course of gene expression in primary hepatocytes, we isolated RNA from hepatocytes at multiple time points during the isolation: (a) directly after perfusion and before passing the cell suspension through a filter; (b) after the filter; (c) after washing cells; (d) 2 hours after plating; (e) 6 hours after plating; (f) 18 hours after plating; and (g) 24 hours after plating.

Uptake assay for radiolabeled HDL with hepatocytes. To determine cellular uptake of radiolabeled HDL, hepatocytes incubated $\left(37^{\circ} \mathrm{C}, 10,30\right.$, or 120 minutes) in DMEM containing BSA $(5 \mathrm{mg} / \mathrm{ml})$, penicillin $(100 \mu \mathrm{g} / \mathrm{ml})$, streptomycin $(100 \mu \mathrm{g} / \mathrm{ml})$, and ${ }^{125} \mathrm{I}-\mathrm{TC}-/\left[{ }^{3} \mathrm{H}\right]$ CEt-WT-HDL (39); the respective incubation time and the concentration of labeled HDL are given in the figure legends. Finally, cells were harvested by trypsin/EDTA ( $1 \times$ trypsin $0.05 \%$, EDTA $0.53 \mathrm{mM})$ treatment, and cellular uptake of HDL tracers was measured. ${ }^{125} \mathrm{I}$ was directly radioassayed, and $\left[{ }^{3} \mathrm{H}\right]$ was analyzed after lipid extraction (85). Uptake of ${ }^{125} \mathrm{I}-\mathrm{TC}-/\left[{ }^{3} \mathrm{H}\right] \mathrm{CEt}-\mathrm{WT}-\mathrm{HDL}$ by cells is shown in terms of apparent HDL particle uptake, expressed as $\operatorname{HDL}$ protein $(15,39)$. This was done to compare the uptake of both tracers on a common basis. The uptake of HDL holoparticles is represented by ${ }^{125} \mathrm{I}-\mathrm{TC}$, and the difference between $\left[{ }^{3} \mathrm{H}\right] \mathrm{CEt}$ and ${ }^{125} \mathrm{I}$-TC yields apparent selective HDL-CE uptake by cells (36).

Motif analysis. To determine the number of potential FoxO-binding motifs within or near the Scarb1 and Lipc sequences, we obtained the entire mouse gene sequences of Scarb1 and Lipc (including intronic regions), along with $50 \mathrm{~kb}$ of sequence upstream of each gene's transcription start site. Sequences were obtained from the UCSC Genome Browser (https://genome.ucsc.edu) and were analyzed using HOMER algorithm software (41), which provided the coordinates of all the potential FoxO-binding motifs within this selected region.

Statistics. Data are presented as the mean \pm SEM. Data were analyzed by 2-tailed Student's $t$ tests, or 1-way or 2-way ANOVA followed by a post hoc test in $\mathrm{R}$, as appropriate. Statistical tests used for each comparison are listed in the figure legends. A $P$ value of less than 0.05 was considered statistically significant.

Study approval. All animal protocols were approved by the IACUCs of the University Hospital Hamburg and the Columbia College of Physicians and Surgeons.

\section{Author contributions}

RAH conceived of the study, designed and performed experiments, and wrote the manuscript. SXL and FR designed and performed experiments and wrote the manuscript. RR analyzed the tracer data. $\mathrm{MH}, \mathrm{CS}, \mathrm{GB}, \mathrm{AWF}, \mathrm{JH}, \mathrm{JL}$, and IH performed experiments. HNG and JH provided laboratory equipment and contributed to discussions. All authors edited the manuscript.

\section{Acknowledgments}

The authors gratefully acknowledge Alan Tall (Columbia University), Marit Westerterp (Columbia University and University of Groningen), Richard Deckelbaum, Domenico Accili, and Utpal Pajvani from Columbia University for their insightful comments. We also acknowledge the technical assistance of S. Ehret, E.M. Azizi, B. Henkel, M. Thiel (all from University Medical Center Hamburg Eppendorf, Hamburg, Germany), J. Lee, T. Kolar, and A. Flete (all from Columbia University). We thank Richard E. Morton and Diane Greene from the Cleveland Clinic, Cleveland, $\mathrm{OH}$, USA, who donated CETP for radiolabeling, and Ira Goldberg, Joseph Obunike (both from New York University), David Thomas, and Matthew Mollusky (both from Columbia University), who provided experimental advice. This work was funded by the NIH R01HL125649 (to RAH), F31HL132484 (to SXL), and R35HL135833 (to HNG); the New York Community Trust P16000716 (to RAH); the German Diabetes Association (DDG) (to FR); Muehlbauer Stiftung, Hamburg (to MH); the DFG (HE3645/71) and the EU FP7 project RESOLVE (FP7-HEALTH-2012-305707) (to JH); and D.A.C.H. Gesellschaft für Prävention (to CS).

Address correspondence to: Rebecca A. Haeusler, 1150 Saint Nicholas Avenue, Room 303A, New York, New York 10032, USA. Phone: 212.851.4899; Email: rah2130@columbia.edu. Or to: Franz Rinninger, University Medical Center Eppendorf, Martinistrasse 52, Hamburg 20146, Germany. Phone: 49.40.7410.5.2905; Email: rinninger@uke.de.
1. Accili D, Arden KC. FoxOs at the crossroads of cellular metabolism, differentiation, and transformation. Cell. 2004;117(4):421-426.

2. Nakae J, et al. Regulation of insulin action and pancreatic beta-cell function by mutated alleles of the gene encoding forkhead transcription factor Foxo1. Nat Genet. 2002;32(2):245-253.

3. O-Sullivan I, et al. FoxO1 integrates direct and indirect effects of insulin on hepatic glucose production and glucose utilization. Nat Commun. 2015;6:7079.

4. Lu M, et al. Insulin regulates liver metabolism in vivo in the absence of hepatic Akt and Foxo1. Nat Med. 2012;18(3):388-395.

5. Dong XC, et al. Inactivation of hepatic Foxo1 by insulin signaling is required for adaptive nutrient homeostasis and endocrine growth regulation. Cell Metab. 2008;8(1):65-76.

6. Brunet A, et al. Akt promotes cell survival by phosphorylating and inhibiting a Forkhead transcription factor. Cell. 1999;96(6):857-868.

7. Nakae J, Park BC, Accili D. Insulin stimulates phosphorylation of the forkhead transcription factor FKHR on serine 253 through a Wortmannin-sensitive pathway. J Biol Chem. 1999;274(23):15982-15985.

8. Haeusler RA, Kaestner KH, Accili D. FoxOs function synergistically to promote glucose production. J Biol Chem. 2010;285(46):35245-35248.

9. Haeusler RA, et al. Integrated control of hepatic lipogenesis versus glucose production requires FoxO transcription factors. Nat Commun.
2014;5:5190.

10. Haeusler RA, Pratt-Hyatt M, Welch CL, Klaassen CD, Accili D. Impaired generation of 12-hydroxylated bile acids links hepatic insulin signaling with dyslipidemia. Cell Metab. 2012;15(1):65-74.

11. Zhang W, et al. FoxO1 regulates multiple metabolic pathways in the liver: effects on gluconeogenic, glycolytic, and lipogenic gene expression. J Biol Chem. 2006;281(15):10105-10117.

12. Tao R, Wei D, Gao H, Liu Y, DePinho RA, Dong XC. Hepatic FoxOs regulate lipid metabolism via modulation of expression of the nicotinamide phosphoribosyltransferase gene. J Biol Chem. 2011;286(16):14681-14690.

13. Kozarsky KF, Donahee MH, Rigotti A, Iqbal SN, Edelman ER, Krieger M. Overexpression 
of the HDL receptor SR-BI alters plasma HDL and bile cholesterol levels. Nature. 1997;387(6631):414-417.

14. Rigotti A, Trigatti BL, Penman M, Rayburn H, Herz J, Krieger M. A targeted mutation in the murine gene encoding the high density lipoprotein (HDL) receptor scavenger receptor class $\mathrm{B}$ type I reveals its key role in HDL metabolism. Proc Natl Acad Sci US A. 1997;94(23):12610-12615.

15. Glass C, Pittman RC, Civen M, Steinberg D. Uptake of high-density lipoprotein-associated apoprotein A-I and cholesterol esters by 16 tissues of the rat in vivo and by adrenal cells and hepatocytes in vitro. J Biol Chem. 1985;260(2):744-750.

16. Acton S, Rigotti A, Landschulz KT, Xu S, Hobbs $\mathrm{HH}$, Krieger M. Identification of scavenger receptor SR-BI as a high density lipoprotein receptor. Science. 1996;271(5248):518-520.

17. Jansen H, Verhoeven AJ, Sijbrands EJ. Hepatic lipase: a pro- or anti-atherogenic protein? J Lipid Res. 2002;43(9):1352-1362.

18. Doolittle MH, Wong H, Davis RC, Schotz MC. Synthesis of hepatic lipase in liver and extrahepatic tissues. J Lipid Res. 1987;28(11):1326-1334.

19. Ji ZS, Dichek HL, Miranda RD, Mahley RW. Heparan sulfate proteoglycans participate in hepatic lipaseand apolipoprotein E-mediated binding and uptake of plasma lipoproteins, including high density lipoproteins. J Biol Chem. 1997;272(50):31285-31292.

20. Karackattu SL, Trigatti B, Krieger M. Hepatic lipase deficiency delays atherosclerosis, myocardial infarction, and cardiac dysfunction and extends lifespan in SR-BI/apolipoprotein E double knockout mice. Arterioscler Thromb Vasc Biol. 2006;26(3):548-554.

21. Amar MJ, et al. Hepatic lipase facilitates the selective uptake of cholesteryl esters from remnant lipoproteins in apoE-deficient mice. J Lipid Res. 1998;39(12):2436-2442.

22. Dugi KA, et al. In vivo evidence for both lipolytic and nonlipolytic function of hepatic lipase in the metabolism of HDL. Arterioscler Thromb Vasc Biol. 2000;20(3):793-800.

23. Dichek HL, et al. Overexpression of hepatic lipase in transgenic mice decreases apolipoprotein B-containing and high density lipoproteins. Evidence that hepatic lipase acts as a ligand for lipoprotein uptake. J Biol Chem. 1998;273(4):1896-1903.

24. Brundert M, Heeren J, Greten H, Rinninger F. Hepatic lipase mediates an increase in selective uptake of HDL-associated cholesteryl esters by cells in culture independent from SR-BI. J Lipid Res. 2003;44(5):1020-1032.

25. Out R, et al. Scavenger receptor class B type I is solely responsible for the selective uptake of cholesteryl esters from HDL by the liver and the adrenals in mice. JLipid Res. 2004;45(11):2088-2095.

26. Brundert $M$, et al. Scavenger receptor class $B$ type I mediates the selective uptake of high-density lipoprotein-associated cholesteryl ester by the liver in mice. Arterioscler Thromb Vasc Biol. 2005;25(1):143-148.

27. Lambert $\mathrm{G}$, et al. Hepatic lipase deficiency decreases the selective uptake of HDL-cholesteryl esters in vivo. J Lipid Res. 2000;41(5):667-672.
28. Homanics GE, et al. Mild dyslipidemia in mice following targeted inactivation of the hepatic lipase gene. J Biol Chem. 1995;270(7):2974-2980

29. Yamashita S, Sprecher DL, Sakai N, Matsuzawa Y, Tarui S, Hui DY. Accumulation of apolipoprotein E-rich high density lipoproteins in hyperalphalipoproteinemic human subjects with plasma cholesteryl ester transfer protein deficiency. JClin Invest. 1990;86(3):688-695.

30. Vaisman BL, et al. Overexpression of human lecithin cholesterol acyltransferase leads to hyperalphalipoproteinemia in transgenic mice. J Biol Chem. 1995;270(20):12269-12275.

31. Nakashima Y, Plump AS, Raines EW, Breslow JL, Ross R. ApoE-deficient mice develop lesions of all phases of atherosclerosis throughout the arterial tree. Arterioscler Thromb. 1994;14(1):133-140

32. Bérard AM, et al. High plasma HDL concentration associated with enhanced atherosclerosis in transgenic mice overexpressing lecithin-cholesteryl acyltransferase. Nat Med.1997;3(7):744-749.

33. van Haperen R, et al. Increased risk of atherosclerosis by elevated plasma levels of phospholipid transfer protein. J Biol Chem. 2002;277(50):48938-48943.

34. Hocquette JF, Graulet B, Olivecrona T. Lipoprotein lipase activity and mRNA levels in bovine tissues. Comp Biochem Physiol B, Biochem Mol Biol.1998;121(2):201-212.

35. Peterson J, Bengtsson-Olivecrona G, Olivecrona T. Mouse preheparin plasma contains high levels of hepatic lipase with low affinity for heparin. Biochim Biophys Acta. 1986;878(1):65-70.

36. Pittman RC, Knecht TP, Rosenbaum MS, Taylor CA. A nonendocytotic mechanism for the selective uptake of high density lipoprotein-associated cholesterol esters. J Biol Chem. 1987;262(6):2443-2450.

37. Rinninger F, et al. High density lipoprotein metabolism in low density lipoprotein receptor-deficient mice. J Lipid Res. 2014;55(9):1914-1924.

38. Brundert $\mathrm{M}$, et al. Scavenger receptor CD36 mediates uptake of high density lipoproteins in mice and by cultured cells. J Lipid Res. 2011;52(4):745-758.

39. Rinninger F, et al. Selective uptake of high-density lipoprotein-associated cholesteryl esters by human hepatocytes in primary culture. Hepatology. 1994;19(5):1100-1114.

40. Tsukamoto K, Buck L, Inman W, Griffith L, Kocher O, Krieger M. Challenges in using cultured primary rodent hepatocytes or cell lines to study hepatic HDL receptor SR-BI regulation by its cytoplasmic adaptor PDZK1. PLoS One 2013;8(7):e69725.

41. Heinz S, et al. Simple combinations of lineage-determining transcription factors prime cis-regulatory elements required for macrophage and B cell identities. Mol Cell. 2010;38(4):576-589.

42. Ikemoto $\mathrm{M}$, et al. Identification of a PDZ-domain-containing protein that interacts with the scavenger receptor class B type I. Proc Natl Acad Sci U S A. 2000;97(12):6538-6543.

43. Kocher O, Yesilaltay A, Cirovic C, Pal R, Rigotti A, Krieger M. Targeted disruption of the PDZK1 gene in mice causes tissue-specific depletion of the high density lipoprotein receptor scavenger receptor class B type I and altered lipoprotein metabolism. JBiol Chem. 2003;278(52):52820-52825.
44. Lambert G, Chase MB, Dugi K, Bensadoun A, Brewer HB, Santamarina-Fojo S. Hepatic lipase promotes the selective uptake of high density lipoprotein-cholesteryl esters via the scavenger receptor B1. J Lipid Res. 1999;40(7):1294-1303.

45. Teslovich TM, et al. Biological, clinical and population relevance of 95 loci for blood lipids. Nature. 2010;466(7307):707-713.

46. Kathiresan S, et al. Six new loci associated with blood low-density lipoprotein cholesterol, high-density lipoprotein cholesterol or triglycerides in humans. Nat Genet. 2008;40(2):189-197.

47. Zanoni P, et al. Rare variant in scavenger receptor BI raises HDL cholesterol and increases risk of coronary heart disease. Science. 2016;351(6278):1166-1171.

48. Demant T, et al. Lipoprotein metabolism in hepatic lipase deficiency: studies on the turnover of apolipoprotein B and on the effect of hepatic lipase on high density lipoprotein. J Lipid Res. 1988;29(12):1603-1611.

49. Carlson LA, Holmquist L, Nilsson-Ehle P. Deficiency of hepatic lipase activity in post-heparin plasma in familial hyper-alpha-triglyceridemia. Acta Med Scand.1986;219(5):435-447.

50. Breckenridge WC, et al. Lipoprotein abnormalities associated with a familial deficiency of hepatic lipase. Atherosclerosis. 1982;45(2):161-179.

51. Graf GA, et al. ABCG5 and ABCG8 are obligate heterodimers for protein trafficking and biliary cholesterol excretion. J Biol Chem. 2003;278(48):48275-48282.

52. Yu L, et al. Expression of ABCG5 and ABCG8 is required for regulation of biliary cholesterol secretion. J Biol Chem. 2005;280(10):8742-8747.

53. Schwarz M, et al. Disruption of cholesterol 7alpha-hydroxylase gene in mice. II. Bile acid deficiency is overcome by induction of oxysterol 7alpha-hydroxylase. J Biol Chem. 1996;271(30):18024-18031.

54. Russell DW. The enzymes, regulation, and genetics of bile acid synthesis. Annu Rev Biochem. 2003;72:137-174.

55. Biddinger SB, et al. Hepatic insulin resistance directly promotes formation of cholesterol gallstones. Nat Med.2008;14(7):778-782.

56. Shin DJ, Osborne TF. FGF15/FGFR4 integrates growth factor signaling with hepatic bile acid metabolism and insulin action. J Biol Chem. 2009;284(17):11110-11120.

57. Li T, Kong X, Owsley E, Ellis E, Strom S, Chiang JY. Insulin regulation of cholesterol 7alphahydroxylase expression in human hepatocytes: roles of forkhead box $\mathrm{O} 1$ and sterol regulatory element-binding protein 1c. J Biol Chem. 2006;281(39):28745-28754.

58. Li T, et al. Forkhead box transcription factor O1 inhibits cholesterol 7alpha-hydroxylase in human hepatocytes and in high fat diet-fed mice. Biochim Biophys Acta. 2009;1791(10):991-996.

59. Nakae J, Kitamura T, Silver DL, Accili D. The forkhead transcription factor Foxo1 (Fkhr) confers insulin sensitivity onto glucose-6-phosphatase expression. JClin Invest. 2001;108(9):1359-1367.

60. Biddinger SB, et al. Hepatic insulin resistance is sufficient to produce dyslipidemia and susceptibility to atherosclerosis. Cell Metab. 
2008;7(2):125-134.

61. Matsumoto M, Pocai A, Rossetti L, Depinho RA, Accili D. Impaired regulation of hepatic glucose production in mice lacking the forkhead transcription factor Foxo1 in liver. Cell Metab. 2007;6(3):208-216.

62. Ai D, et al. Regulation of hepatic LDL receptors by mTORC1 and PCSK9 in mice. JClin Invest. 2012;122(4):1262-1270.

63. Crestani M, Stroup D, Chiang JY. Hormonal regulation of the cholesterol 7 alpha-hydroxylase gene (CYP7). J Lipid Res. 1995;36(11):2419-2432.

64. Gibbons GF. Regulation of fatty acid and cholesterol synthesis: co-operation or competition? Prog Lipid Res. 2003;42(6):479-497.

65. Lin HV, Accili D. Hormonal regulation of hepatic glucose production in health and disease. Cell Metab. 2011;14(1):9-19.

66. Krauss RM. Lipids and lipoproteins in patients with type 2 diabetes. Diabetes Care. 2004;27(6):1496-1504.

67. Baynes C, et al. The role of insulin insensitivity and hepatic lipase in the dyslipidaemia of type 2 diabetes. Diabet Med. 1991;8(6):560-566.

68. Berk-Planken II, Hoogerbrugge N, Stolk RP, Bootsma AH, Jansen H, DALI Study Group. Atorvastatin dose-dependently decreases hepatic lipase activity in type 2 diabetes: effect of sex and the LIPC promoter variant. Diabetes Care. 2003;26(2):427-432.

69. Arai T, et al. Decreased selective uptake of high density lipoprotein cholesteryl esters in apolipoprotein E knock-out mice. Proc Natl Acad Sci US A.
1999;96(21):12050-12055.

70. Thuren T, Sisson P, Waite M. Activation of hepatic lipase catalyzed phosphatidylcholine hydrolysis by apolipoprotein E. Biochim Biophys Acta. 1991;1083(2):217-220.

71. Thuren T, Weisgraber KH, Sisson P, Waite M. Role of apolipoprotein $\mathrm{E}$ in hepatic lipase catalyzed hydrolysis of phospholipid in high-density lipoproteins. Biochemistry. 1992;31(8):2332-2338.

72. Van Eck M, et al. Differential effects of scavenger receptor BI deficiency on lipid metabolism in cells of the arterial wall and in the liver. J Biol Chem. 2003;278(26):23699-23705.

73. Lewis GF, Rader DJ. New insights into the regulation of HDL metabolism and reverse cholesterol transport. Circ Res. 2005;96(12):1221-1232.

74. Tall AR. An overview of reverse cholesterol transport. Eur Heart J. 1998;19 Suppl A:A31-A35.

75. Rader DJ, Alexander ET, Weibel GL, Billheimer J, Rothblat GH. The role of reverse cholesterol transport in animals and humans and relationship to atherosclerosis. JLipid Res. 2009;50 Suppl:S189-S194.

76. Rader DJ, Tall AR. The not-so-simple HDL story: Is it time to revise the HDL cholesterol hypothesis? Nat Med. 2012;18(9):1344-1346.

77. Dorner M, et al. A genetically humanized mouse model for hepatitis $\mathrm{C}$ virus infection. Nature. 2011;474(7350):208-211.

78. Jiao S, Cole TG, Kitchens RT, Pfleger B, Schonfeld G. Genetic heterogeneity of lipoproteins in inbred strains of mice: analysis by gel-permeation chromatography. Metab Clin Exp.
1990;39(2):155-160.

79. Cook JR, Matsumoto M, Banks AS, Kitamura T, Tsuchiya K, Accili D. A mutant allele encoding DNA binding-deficient FoxO1 differentially regulates hepatic glucose and lipid metabolism. Diabetes. 2015;64(6):1951-1965.

80. Nilsson-Ehle P, Schotz MC. A stable, radioactive substrate emulsion for assay of lipoprotein lipase. J Lipid Res. 1976;17(5):536-541.

81. Henderson AD, Richmond W, Elkeles RS. Hepatic and lipoprotein lipases selectively assayed in postheparin plasma. Clin Chem. 1993;39(2):218-223.

82. Havel RJ, Eder HA, Bragdon JH. The distribution and chemical composition of ultracentrifugally separated lipoproteins in human serum. JClin Invest. 1955;34(9):1345-1353.

83. Pittman RC, Taylor CA. Methods for assessment of tissue sites of lipoprotein degradation. Meth Enzymol. 1986;129:612-628.

84. Morton RE, Zilversmit DB. Inter-relationship of lipids transferred by the lipid-transfer protein isolated from human lipoprotein-deficient plasma. J Biol Chem. 1983;258(19):11751-11757.

85. Dole VP. A relation between non-esterified fatty acids in plasma and the metabolism of glucose. J Clin Invest. 1956;35(2):150-154.

86. Le NA, Ramakrishnan R, Dell RB, Ginsberg HN, Brown WV. Kinetic analysis using specific radioactivity data. Meth Enzymol. 1986;129:384-395.

87. Silver DL, Wang N, Tall AR. Defective HDL particle uptake in ob/ob hepatocytes causes decreased recycling, degradation, and selective lipid uptake. J Clin Invest. 2000;105(2):151-159. 